\title{
IUGR impairs cardiomyocyte growth and maturation in fetal sheep
}

\author{
Sonnet S Jonker1, Daniel Kamna', Dan LoTurco², Jenai Kailey² and Laura D Brown² \\ ${ }^{1}$ Center for Developmental Health, Knight Cardiovascular Institute, Oregon Health \& Science University, Portland, Oregon, USA \\ 2Department of Pediatrics, Perinatal Research Center, Anschutz Medical Campus, University of Colorado, Aurora, Colorado, USA
}

Correspondence should be addressed to S S Jonker: JonkerS@ohsu.edu

\section{Abstract}

Placental insufficiency causes intrauterine growth restriction (IUGR), a common

\section{Key Words}

complication of pregnancy. In skeletal muscle, IUGR reduces fetal myofibril size, reduces myoblast proliferation and reduces expression of genes in cell cycle regulation clusters. The myocardium is striated like skeletal muscle, and IUGR also reduces cell cycle activity and maturation in cardiomyocytes, despite cardiac output preferentially directed to the coronary circulation. We hypothesized that cardiomyocyte growth restriction would be accompanied by similar changes in cell cycle regulation genes and would reduce cardiomyocyte cell cycle activity, number, maturity and size. Pregnant ewes were housed in elevated ambient temperatures from $\sim 40$ to $\sim 115$ days of gestation (dGA) to produce placental insufficiency and IUGR; fetal hearts were studied at $~ 134 \mathrm{dGA}$. Hearts were biopsied for mRNA analysis and then dissociated into individual myocytes (Control $n=8$; IUGR $n=15$ ) or dissected (Control $n=9$; IUGR $n=13$ ). IUGR fetuses had low circulating insulin and insulin-like growth factor 1 (IGF1) and high circulating cortisol. Bodies and hearts of IUGR fetuses were lighter than those of Controls. Cardiomyocytes of IUGR fetuses were smaller, less mature, less active in the cell cycle and less numerous than in Controls. Further, there was a pattern of downregulation of cell cycle genes in IUGR ventricles. IUGR growth profiles in heart and skeletal muscle suggest similar regulation despite differences in blood and nutrient delivery prioritization. IGF1 signaling is suggested as a mechanism regulating altered growth in IUGR striated muscle and a potential therapeutic candidate.
$\checkmark$ fetus
- IGF
- insulin
- myocardium
- corticosteroids

\section{Introduction}

Intrauterine growth restriction (IUGR) results from inadequate placental function limiting fetal nutrient delivery, impairing normal growth and development (Marconi \& Paolini 2008). Infants affected by placental insufficiency redirect a greater proportion of oxygenated blood flow to the upper body, which enhances nutrient delivery to vital organs, including heart and brain, at the expense of other tissues such as skeletal muscle (Baschat \& Hecher 2004, Bellotti et al. 2004, Brown \& Hay 2016).
These fetal adaptations have life-long health implications, a phenomenon known as the Developmental Origins of Health and Disease first articulated by Barker and colleagues (de Boo \& Harding 2006, Fernandez-Twinn \& Ozanne 2010, Barker \& Thornburg 2013). Placental restriction is associated with obesity, reduced lean body mass, insulin resistance and cardiovascular disease in adulthood (Phillips et al. 1994, Fall 2011, Alexander et al. 2015, Camm et al. 2015). Thus, while the heart 
and skeletal muscle are differently prioritized to receive nutrients during placental insufficiency, there are negative consequences for both following IUGR.

Hearts of fetal humans, sheep, rodents and other mammals grow by myocyte proliferation, terminal differentiation (which is associated with cellular enlargement, multinucleation and cessation of proliferation) and enlargement of both proliferative and terminally differentiated myocytes (Zak 1974, Clubb \& Bishop 1984, Kim et al. 1992, Huttenbach et al. 2001, Burrell et al. 2003, Jonker et al. 2015). Despite shunting shown to maintain coronary perfusion during IUGR in humans and sheep (Baschat \& Hecher 2004, Bellotti et al. 2004, Tare et al. 2014), hearts of fetal sheep with experimental placental insufficiency are reduced in weight (Bubb et al. 2007, Louey et al. 2007, Morrison et al. 2007, Tare et al. 2014). IUGR is associated with less mature cardiomyocytes and reduced proliferation in near-term fetal sheep, while disagreement persists as to whether the cells are smaller in fetal sheep and humans (Takahashi et al. 1995, Murotsuki et al. 1997, Mayhew et al. 1999, Bubb et al. 2007, Louey et al. 2007, Morrison et al. 2007, Botting et al. 2014).

Cardiac and skeletal muscle are both striated muscle, characterized by the organization of contractile proteins into sarcomeres, an abundance of mitochondria and (in many species, including humans and sheep) multinucleation on maturity (Adler et al. 1996). Unlike fetal cardiac muscle, in which working myocytes undergo cytokinesis, skeletal muscle grows by proliferation of myoblasts and their subsequent differentiation and fusion to form multinucleated myotubes (Brown \& Hay 2016). Also unlike the heart, skeletal muscle blood flow is reduced in IUGR, leading to a substantial reduction in oxygen and amino acid delivery (Poudel et al. 2015, Rozance et al. 2018); total mass and cross-sectional area of hindlimb muscles are consequently reduced (Soto et al. 2017, Rozance et al. 2018). Myoblasts capable of proliferating are maintained proportional to total number of nuclei and even enhanced relative to myofiber number (indicating immaturity), but cell cycle activity in those myoblasts is reduced (Yates et al. 2014, Soto et al. 2017). Pathway analysis in near-term IUGR skeletal muscle found decreased expression of clusters of genes related to proliferation and differentiation (Soto et al. 2017).

We hypothesized that in near-term fetuses with severe IUGR we would find ventricular cardiomyocyte immaturity, reduced proliferation and suppression of intracellular growth regulatory pathways similar to those suppressed in skeletal muscle (Brown \& Hay 2016,
Soto et al. 2017). To test this hypothesis, we used a wellestablished sheep model of chronic, progressive placental insufficiency that results in severe IUGR (Thureen et al. 1992, Limesand et al. 2007, Regnault et al. 2007). Placental insufficiency is initiated mid-gestation to reduce placental transfer of oxygen, amino acids and glucose similar to that experienced by the human IUGR fetus (Bell et al. 1987, Barry et al. 2008). We examined growth characteristics of cardiomyocytes and mRNA levels of genes that regulate the cardiomyocyte cell cycle.

\section{Materials and methods}

\section{Animal model}

Animal use was approved by the Institutional Animal Care and Use Committee of the University of Colorado, Denver.

Columbia-Rambouillet sheep (Ovis aries) with singleton pregnancies were studied at the University of Colorado Perinatal Research Center as previously described (Soto et al. 2017). The fetuses in this study were included in previously published studies (Brown et al. 2012, Culpepper et al. 2016, Rozance et al. 2018). In brief, pregnant ewes were housed in environmental chambers with elevated ambient temperatures $\left(40^{\circ} \mathrm{C}\right.$ for $12 \mathrm{~h} ; 35^{\circ} \mathrm{C}$ for $12 \mathrm{~h}$ ) and $40 \%$ humidity from $\sim 40$-day gestation (dGA, term $=147 \mathrm{dGA}$ ) to $\sim 115 \mathrm{dGA}$ to produce placental insufficiency and IUGR, after which they were housed in ambient temperatures and humidity (IUGR, $n=15$ ). Control ewes were housed in the same facility at ambient temperatures and normal humidity (Control, $n=8$ ). All sheep had access to water ad libitum. Maternal feed intake was matched on an absolute basis between sheep in the Control and IUGR groups (maternal weight-adjusted feed intake did not differ between groups).

Animals underwent surgery for fetal and maternal catheter placement as previously described, including catheterization of the fetal abdominal aorta (Soto et al. 2017). Briefly, ewes were fasted for $24 \mathrm{~h}$ and water deprived for $12 \mathrm{~h}$ prior to surgery. Diazepam $(0.2 \mathrm{mg} / \mathrm{kg})$ and ketamine $(20 \mathrm{mg} / \mathrm{kg})$ were administered intravenously, and then ewes were maintained throughout surgery on isoflurane inhalation anesthesia (2-4\%). Maternal analgesia was provided with intramuscular Banamine $(1.1 \mathrm{mg} / \mathrm{kg}$ ) (Merck Animal Health USA, Madison, NJ, USA). Surgical recovery was at least 5 days.

On the morning of tissue collection, fetal arterial blood was assayed for measurement of $\mathrm{pH}$, partial pressure of $\mathrm{CO}_{2}\left(\mathrm{PCO}_{2}\right)$, partial pressure of $\mathrm{O}_{2}\left(\mathrm{PO}_{2}\right)$, 
$\mathrm{O}_{2}$ saturation, $\mathrm{O}_{2}$ content, hemoglobin, insulin, insulinlike growth factor 1 (IGF1), norepinephrine and cortisol using biochemical methods previously described (Limesand et al. 2006, Brown et al. 2012).

\section{Fetal heart collection}

Animals were killed by intravenous pentobarbital sodium (Fatal Plus; Bortech Pharmaceuticals, Dearborn, MI, USA). The fetus was weighed, and the heart was immediately excised. Blood was flushed from fetal hearts with a heparin-containing Tyrode's solution (Jonker et al. 2007). As the high-pressure pumping chambers, we focused on the ventricles. Mid-ventricular biopsies were excised and frozen, and wound edges were sealed with cyanoacrylate. Hearts were enzymatically dissociated and cells were fixed with formaldehyde as previously described (Jonker et al. 2007). As ventricular wall weight cannot be obtained from dissociated hearts, contemporaneous groups of Control and IUGR age-matched fetuses with similar physiological and physical parameters were used to obtain ventricular wall weights (Control $n=9$, IUGR $n=13$ ) as previously described (Jonker et al. 2007).

\section{Cardiomyocyte measurements}

Length and width measurements were obtained from random, non-repeating photomicrographs from no fewer than 90 isolated cardiomyocytes separately from each ventricular wall, as previously described (Jonker et al. 2007). A shape factor, measured from no fewer than ten mononucleated and binucleated myocytes per fetal ventricular wall, was used to calculate myocyte volume from length and width measurements (Jonker et al. 2007).

The number of nuclei in at least 300 myocytes from each ventricular wall of each animal was tabulated to determine the fractions of mono-, bi-, and quadrinucleated cells.

Detection of anti-Ki-67 antibody binding (MIB-1, Dako) was used to determine cell cycle activity from $\sim 500$ cells per ventricular wall per animal as previously described (Jonker et al. 2007).

\section{Cardiac number myocyte quantification}

Cardiomyocyte number was calculated as previously described (Jonker et al. 2007, 2015), with minor modifications. The proportional relationship between ventricular wall weight and heart weight was derived from values measured from a subset of animals (Control, $n=9$;
IUGR, $n=13)$. This was used to calculate ventricular wall weights from total heart weight for each enzymatically dissociated heart. Wall weights were multiplied by the proportion of myocardium, which is composed of myocytes (Smolich et al. 1989), and divided by the specific gravity of $1.05 \mathrm{~g} / \mathrm{mL}$, which was then divided by the proportionally represented myocyte volumes (Jonker et al. 2007, 2015) to yield myocyte number per wall. As there were not enough quadrinucleated cells to obtain morphometric measurements, and as they have been found previously to be twice the volume of binucleated cells (Jonker et al. 2015), they were included in calculations using twice the volume of binucleated cells.

\section{RNA extraction and quantitative real-time PCR analysis}

Total RNA was isolated from myocardial biopsies, reverse transcribed and used in qPCR using the $\Delta \Delta C T$ method (Lightcycler 480 II; Roche Life Science) as previously described (Brown et al. 2014, Soto et al. 2017). Genes for analysis were selected based on the KEGG pathway analysis for fetal sheep IUGR skeletal muscle previously published, in addition to some other key cell cycle regulators (Soto et al. 2017). Those primers for qPCR assays that were not published previously (Soto et al. 2017) are provided in Table 1. mRNA expression levels of reference genes did not vary by treatment or ventricular wall; therefore, all experimental genes are expressed as a ratio with the equalweighted average of the reference genes. mRNA levels are expressed relative to average LV Control values.

\section{Statistical analysis}

Comparisons of blood parameters and necropsy weights were by Student's unpaired t-test (Prism 6, GraphPad Software). Sex distribution was assessed using chisquare test. Treatment (Control, IUGR), ventricular wall (LV, septum, RV) and sex (male, female) were initially screened as main effects by Student's unpaired $t$-test; although sex differences do sometimes emerge in fetal cardiac studies (Lumbers et al. 2009, Botting et al. 2018), no significant sex effect was found in this dataset; thus, sex was not included in the final analysis. The effect of sex was not evaluated for mRNA gene expression due to limited sample size. Two-way ANOVA was used to determine the effects of treatment and ventricular wall on cardiomyocyte and mRNA parameters. When indicated by a significant interaction term, multiple comparisons were conducted with Holm-Sidak correction. Pearson's 
Table 1 Sequences of primers used for qPCR.

Cyclin A2 (Ccna2)

Cyclin D1 (Ccnd1)

Cyclin D2 (Ccnd2)

Cyclin-dependent kinase $4(C d k 4)$

Cyclin-dependent kinase 6 (Cdk6)

Activator of $\mathrm{S}$ phase kinase ( $\mathrm{Dbf} 4)$

Myeloid ecotropic viral integration site 1 homolog (Meis1)

Myeloid leukemia factor 2 (M/f2)

Cyclin-dependent kinase inhibitor $1 \mathrm{~A}(\mathrm{p} 21)$

Cyclin-dependent kinase inhibitor 1B (p27)

Ribosomal protein L32 ( $R p / 32)$

Ribosomal protein L37a (Rp/37a)

Transcription factor Dp-1 (Tfdp1)

Protein kinase C inhibitor protein-1 (Ywhaz)

\begin{tabular}{l}
\hline Forward \\
CCTGCAAACTGCAAAGTTGAA \\
ACTACCTGGACCGCTTCCT \\
TCCTCTCGCCATCAATTACC \\
ATTTCCTTCATGCCAACTGCA \\
GCATCGTGATCTAAAACCACA \\
ATCTGGGAGGGCGAGTTGAAGAAT \\
ATATCATGAGGGCGTGGCTG \\
CTCAGCATCACAGATGGCAA \\
GAGGACCACTTGGACCTGT \\
GCTTGCCCGAGTTCTACTAC \\
AATCAAGCGGAACTGGCG \\
ACCAAGAAGGTCGGAATCGT \\
AGGTCTTCATCGACCAGAACCTCA \\
CAAACGCTTCACAAGCAGAGAGCA
\end{tabular}

Reverse

GGTGAAGGTCCAGGAGACA

TTGGAGAGGAAGTGCTCGAT

TCCTGAGGCTTGATGGAGTT

CCAACACTCCACATGTCCAC

GAGTCCAATCACGTCCAAGA

TGAGGTGATGTGGTTTCCGCAGTA

ATAGGTCCTGGTGCCCTGAT

CATGTCGTTCATCATCCCAA

TCTGCGTTTGGAGTGGTAGA

CATTTTCTTCTGTTCTGTTGGC

GGCATTGGGATTGGTGATT

GGCACCACCAGCTACTGTTT

TACCAATCACCACTTGCTGCGAGA

TGCTGTGACTGATCCACAATCCCT correlation coefficients were calculated to explore relationships between circulating hormones and cardiomyocyte parameters in IUGR fetuses; if significant, linear regression was performed to determine if relationships were similar between Control and IUGR fetuses. If not different, regression relationships were determined for all fetuses pooled. $P<0.05$ was considered statistically significant.

\section{Results}

\section{Fetal physiological characteristics}

Gestational age (Control: 134.9 \pm 0.8 , IUGR: 134.2 \pm 1.2 ) and sex distribution (Control: 50\% male, IUGR: 53\% male) were not different between groups. Placental insufficiency reduced fetal arterial $\mathrm{PO}_{2}$, hemoglobin saturation, $\mathrm{O}_{2}$ content and plasma glucose (Table 2). No changes were observed in $\mathrm{pH}, \mathrm{PCO}_{2}$, total hemoglobin or plasma lactate. IUGR reduced fetal arterial plasma insulin and IGF1 levels and increased cortisol and norepinephrine levels.

Placental insufficiency reduced fetal body weight (Fig. 1A) and heart weight (Fig. 1B). The ratio of heartto-body weight was not different, but tended to be lower in IUGR ( $P=0.0613$; Fig. 1C). Because IUGR changed hormone levels, the relationship of heart weight with these factors was tested in IUGR fetuses and found to be correlated with IGF1 ( $r=0.8497, P<0.0001)$ (Fig. 1D).

Ventricular wall weights were reduced by IUGR (main effect, $P<0.0001)$ and affected by anatomical location (main effect, $P<0.0001$ ), but there was no significant interaction between these terms ( $P=0.0619$; Fig. 1E). Wall weights normalized to heart weight were affected by anatomical location only $(P<0.0001)$ (Fig. 1 F).

Table 2 Arterial blood gas and chemistry in control and IUGR fetal sheep aged 134 dGA.

\begin{tabular}{|c|c|c|c|}
\hline & \multicolumn{3}{|c|}{ Comparison of means } \\
\hline & Control $(n=8)$ & IUGR $(n=15)$ & $P$-Value \\
\hline $\mathrm{pH}$ & $7.35 \pm 0.02$ & $7.35 \pm 0.02$ & ns \\
\hline Hemoglobin (mmol/L) & $7.8 \pm 1.6$ & $7.4 \pm 1.0$ & ns \\
\hline $\mathrm{PCO}_{2}(\mathrm{mmHg})$ & $50.7 \pm 2.8$ & $51.5 \pm 2.2$ & ns \\
\hline $\mathrm{PO}_{2}(\mathrm{mmHg})$ & $19.8 \pm 1.6$ & $14.8 \pm 2.8$ & 0.0002 \\
\hline $\mathrm{O}_{2}$ saturation $(\%)$ & $47.6 \pm 5.9$ & $30.7 \pm 10.9$ & 0.0006 \\
\hline $\mathrm{O}_{2}$ content $(\mathrm{mmol} / \mathrm{L})$ & $3.1 \pm 0.5$ & $2.1 \pm 0.9$ & 0.0063 \\
\hline Glucose (mg/dL) & $21 \pm 5$ & $14 \pm 4$ & 0.0019 \\
\hline Lactate (mmol/L) & $2.5 \pm 0.5$ & $2.7 \pm 0.9$ & ns \\
\hline Insulin (ng/mL) & $0.4 \pm 0.2$ & $0.2 \pm 0.1$ & 0.0171 \\
\hline Cortisol (ng/mL) & $9.2 \pm 7.0$ & $23.6 \pm 18.2$ & 0.0431 \\
\hline Norepinephrine $(\mathrm{pg} / \mathrm{mL})$ & $602 \pm 404$ & $1699 \pm 1492$ & 0.0034 \\
\hline IGF1 (ng/mL) & $125 \pm 37$ & $54 \pm 33$ & 0.0001 \\
\hline
\end{tabular}

Groups compared by Student's $t$-test. Data are shown as mean \pm S.D. ns, not significant. 


\begin{tabular}{l|l|l|l|l|} 
Journal of & S S Jonker et al. & $\begin{array}{l}\text { IUGR reduces cardiomyocyte } \\
\text { number }\end{array}$ & $\mathbf{2 3 9 : 2}$ & $\mathbf{2 5 7}$ \\
Endocrinology & &
\end{tabular}
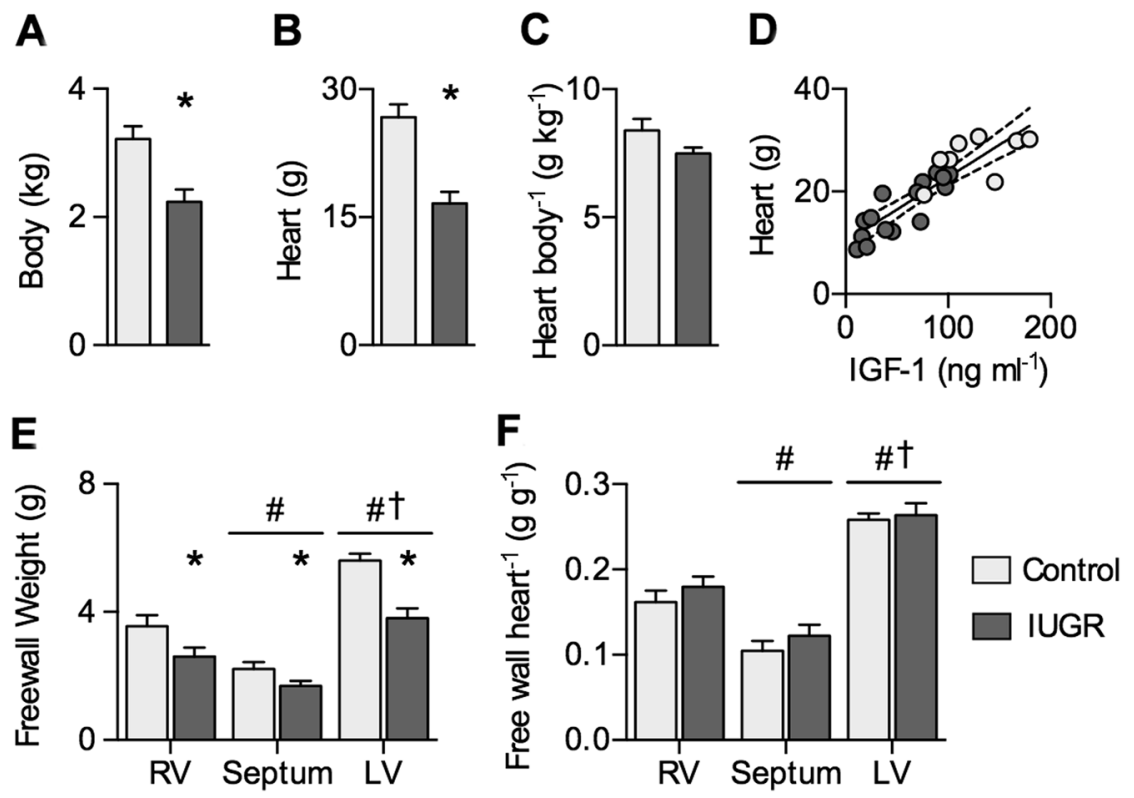

\begin{abstract}
Figure 1
Body and heart weights in Control and IUGR fetal sheep. (A) Body weight, (B) heart weight and (C) heart weight relative to body weight in Control $(n=8)$ and IUGR $(n=15) \sim 134$ dGA fetuses. (D) Following significant correlation within IUGR fetuses between circulating IGF1 and heart weight, regressions on separate treatment groups were not found to be significantly different and a single regression was fit between circulating IGF1 levels and heart weight $(Y=0.1262 X+10.18$, $\left.r^{2}=0.77, P<0.0001\right)$. (E) Ventricular wall weights and $(F)$ wall weights relative to heart weight in Control $(n=9)$ and IUGR $(n=13)$ fetuses at $\sim 134$ dGA. Groups in panels A, B and C compared by Student's $t$-test. Groups in panels $D$ and $E$ compared by 2-way ANOVA and Holm-Sidak test. Different from *Control, \#RV, and +Septum $(P<0.05)$. Data are shown as mean \pm standard deviation.
\end{abstract}

\section{Cardiomyocyte growth and maturation}

The interaction term between treatment and anatomical location of cell origin was not significant for any myocyte measurement.

IUGR reduced cell cycle activity expressed as a percentage of mononucleated myocytes $(P=0.0191$; Fig. 2A). Ventricular source did not affect cell cycle activity $(P=0.0905)$. IUGR reduced the proportion of binucleated myocytes - an index of maturation ( $P=0.0383$; Fig. 3B). Proportion quadrinucleated was not different between groups and was less than 1\% of all cells (data not shown).

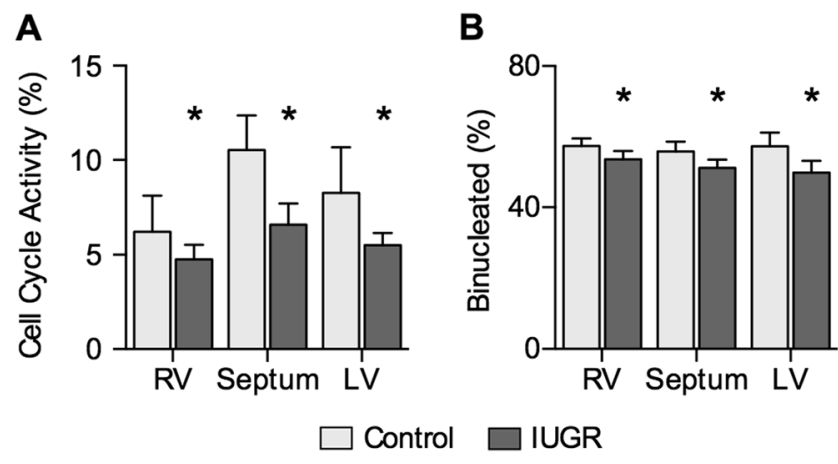

\section{Figure 2}

Cardiomyocyte cell cycle activity and maturation in Control and IUGR fetal sheep. (A) Cell cycle activity, as determined by Ki-67 protein labeling, in Control $(n=8)$ and IUGR (RV and LV $n=13$; Septum $n=14$ ) fetuses at $\sim 134 \mathrm{dGA}$. (B) Cell immaturity, as indicated by proportion binucleate, in IUGR fetuses (LV $n=15, \mathrm{RV}$ and septum $n=14$ ) and Control fetuses $(n=8)$. Groups compared by 2-way ANOVA and Holm-Sidak test. Different from *Control $(P<0.05)$. Data are shown as mean \pm standard deviation.
Mononucleated myocyte lengths were reduced by IUGR $(P=0.0012)$ and were different across the ventricular walls $(P=0.0012)$ (Fig. 3A). IUGR did not affect mononucleated width $(P=0.0612)$, but ventricular origin did $(P<0.0001 ;$ Fig. 3B). Mononucleated myocyte volumes were reduced by IUGR $(P=0.009)$ and different across the ventricular walls $(P<0.0001$; Fig. $3 \mathrm{C})$.

Binucleated myocyte lengths were reduced by IUGR $(P=0.0108)$ and affected by ventricular origin $(P<0.0001$; Fig. 3D). Binucleated widths were not changed by IUGR, but were different across the ventricular walls $(P<0.0001$; Fig. 3E). IUGR reduced binucleated myocyte volumes $(P=0.0196)$, which were also affected by ventricular origin $(P<0.0001$; Fig. 3F).

Cardiomyocyte number was reduced by IUGR $(P=0.0361)$ and different across the ventricular walls $(P<0.0001$; Fig. 4).

\section{Associations between circulating factors and myocyte parameters}

Because IUGR changed circulating hormones, the correlation of cardiomyocyte growth parameters with these factors was tested in IUGR fetuses. IGF1 levels in IUGR fetuses were correlated with myocyte number in the LV $(r=0.6903, P=0.0044)$, septum $(r=0.7388, P=0.0025)$ and RV ( $r=0.5682, P=0.034)$ (Fig. 5).

Insulin levels in IUGR fetuses were correlated with LV binucleate length $(r=0.5763, P=0.0245)$, RV binucleate length $(r=0.5472, \quad P=0.0429), \quad R V$ binucleate width https://joe.bioscientifica.com https://doi.org/10.1530/JOE-18-0382
() 2018 Society for Endocrinology Published by Bioscientifica Ltd. Printed in Great Britain 


\begin{tabular}{|c|c|c|c|c|}
\hline $\begin{array}{l}\text { Journal of } \\
\text { Endocrinology }\end{array}$ & S S Jonker et al. & $\begin{array}{l}\text { IUGR reduces cardiomyocyte } \\
\text { number }\end{array}$ & $239: 2$ & 258 \\
\hline
\end{tabular}

A

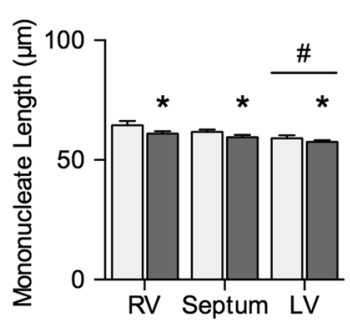

D

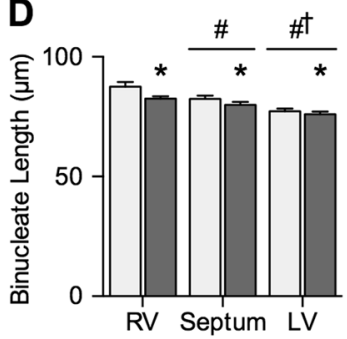

B

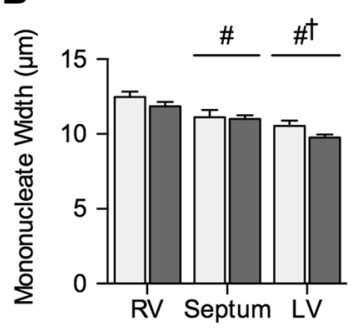

$E$

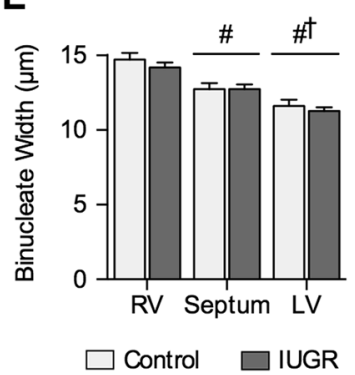

C

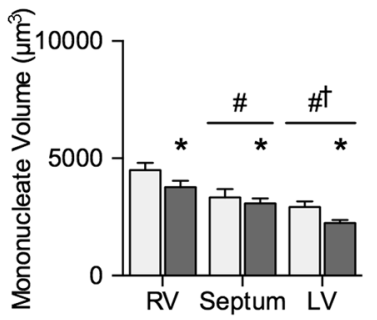

$\mathbf{F}$

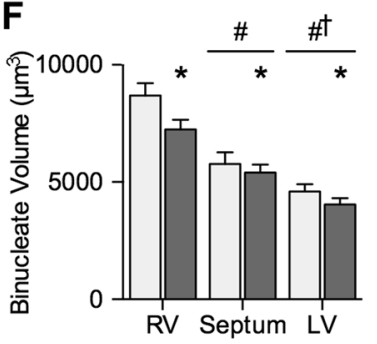

Figure 3

Cardiomyocyte size in Control and IUGR fetal sheep. (A) Mononucleated myocyte length, (B) width, and (C) volume and (D) binucleated myocyte length, $(E)$ width, and $(F)$ volume in Control fetuses $(n=8)$ and IUGR fetuses (LV $n=15$, RV and septum $n=14$ ) at $\sim 134$ dGA. Groups compared by 2-way ANOVA and Holm-Sidak test. Different from *Control, \#RV and †Septum $(P<0.05)$. Data are shown as mean \pm standard deviation. $(r=0.6034, P=0.0223)$ and RV mononucleate length $(r=0.5988, P=0.0237$ ) (Fig. 6). There was a tendency for a correlation with septum binucleate length $(r=0.5067$, $P=0.0644)$. It was determined that the slopes of the regressions binucleate length against insulin levels differed significantly between Control and IUGR fetuses for $\operatorname{LV}(P=0.0181)$ and that the regression for Control fetuses was not significant; therefore, the relationship for the IUGR fetuses alone was determined.

Log-transformed cortisol levels in IUGR fetuses were negatively correlated with LV binucleated width $(r=-0.5312, \quad P=0.0416)$ and RV binucleated length ( $r=-0.6427, P=0.132$ ) (Fig. 7). There were tendencies for correlation with RV proportion binucleated ( $r=0.5291$, $P=0.0517)$ and negative correlation with RV binucleate width $(r=-0.5297, P=0.0514)$.

Log-transformed norepinephrine levels in IUGR fetuses were correlated with RV proportion binucleated ( $r=0.5507, \quad P=0.0413)$, and septum $(r=-0.6112$, $P=0.0202)$. There was a tendency for negative correlation with RV binucleate width ( $r=-0.4684$, $P=0.0912$ ) and binucleate length in the septum ( $r=-0.5193, P=0.0570)$. Linear regression relationships for RV proportion binucleated were not different between Control and IUGR fetuses, but the regression relationship for all fetuses together was not significant. Linear regression relationships for septum proportion binucleated had different intercepts between Control and IUGR fetuses $(P=0.0103)$, and the slope of the regression for the Control relationship was not different from zero. Printed in Great Britain

\section{Cardiac mRNA expression levels}

Reference genes Rpl32, Rpl37a and Mlf2 did not vary with treatment or between ventricles (Table 3).

IUGR reduced the mRNA expression of Ccna2 (cyclin A2) and Ccnb2 (cyclin B2) (Table 3). Treatment interacted with ventricular source for Ccnb1 (cyclin B1) and Ccnd2 (cyclin D2); for both genes, RV expression was lower in IUGR, while RV expression was greater than LV. RV expression was also greater than LV for Ccnb2 (cyclin B2). There was no effect of treatment or ventricle on Ccnd1 (cyclin D1) or Ccne2 (cyclin E2) levels.

IUGR reduced ventricular Cdk1 expression (Table 3). The interaction term was significant for Cdk6; IUGR reduced Cdk6 expression in the RV, and expression was
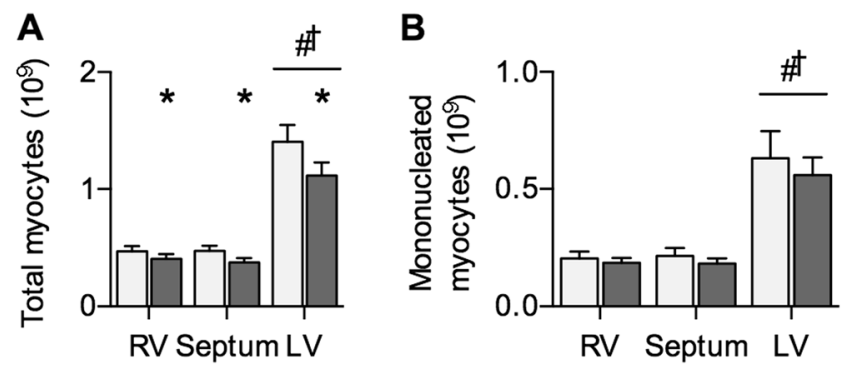

Control

IUGR

\section{Figure 4}

Myocyte number in Control and IUGR fetal sheep. (A) Total myocyte number, and (B) number of mononucleated myocytes in IUGR (LV $n=15$, RV and septum $n=14$ ) and Control fetuses $(n=8)$ at $\sim 134$ dGA. Groups compared by 2-way ANOVA and Holm-Sidak test. Different from *Control, \#RV, +Septum $(P<0.05)$. Data are shown as mean \pm standard deviation. 


\begin{tabular}{l|l|l|l|} 
Journal of & S S Jonker et al. & $\begin{array}{l}\text { IUGR reduces cardiomyocyte } \\
\text { number }\end{array}$ & $\mathbf{2 3 9 : 2}$ \\
Endocrinology & & $\mathbf{2 5 9}$
\end{tabular}
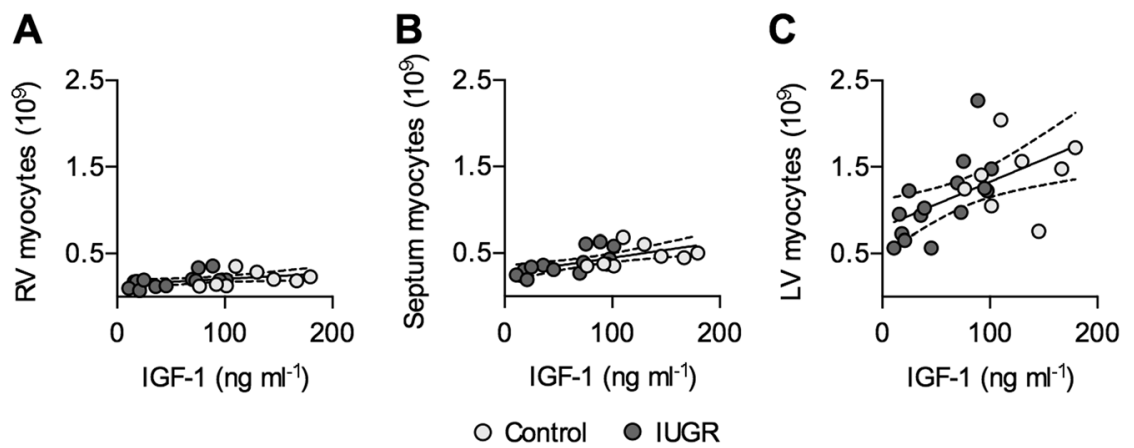

greater in the RV than the LV. There was no effect of treatment or ventricle on Cdk4 levels.

$C d k n 2 c$ (p18) expression was greater in the RV than LV, while Cdkn1a (p21) was lower in the RV (Table 3). There was no effect of treatment or ventricle on $C d k n 1 b$ (p27) levels.

IUGR reduced the expression of Plk1, Cdc20, Mad2, $B u b 1 b$, and Espl1 (Table 3). Treatment interacted with ventricular source for $\mathrm{Dbf} 4$; IUGR reduced $\mathrm{Dbf4}$ expression in the RV, and RV expression was greater than LV. RV expression was also greater than LV for Bub1b and Ywhaz. There was no effect of treatment or ventricle on $C h k 1$.

There was no effect of treatment or ventricle on transcription factors Tfdp1 or Meis1 (Table 3).

\section{Discussion}

We found that near-term fetuses affected by chronic placental insufficiency and IUGR had smaller cardiomyocytes with reduced terminal differentiation and proliferation, and consequently a diminished myocyte complement in the heart. Impaired growth and maturation was found across all ventricular walls, and these differences all contribute to the smaller hearts found in IUGR fetuses. These changes were supported by reduced mRNA expression of cyclins and cell cycle effectors and checkpoint genes in IUGR hearts.

\section{Comparison of the heart and skeletal muscle in IUGR}

Although the work demanded of fetal skeletal muscle is less than that of cardiac muscle, both are types of striated muscle and cellular complements of both are mostly set by the time of birth (Rowe \& Goldspink 1969, Widdowson et al. 1972, Burrell et al. 2003, Bergmann et al. 2015, Jonker et al. 2015). We found previously that skeletal muscle is lighter in IUGR fetuses, the cross-sectional area

Figure 6 plotted with raw data.
A
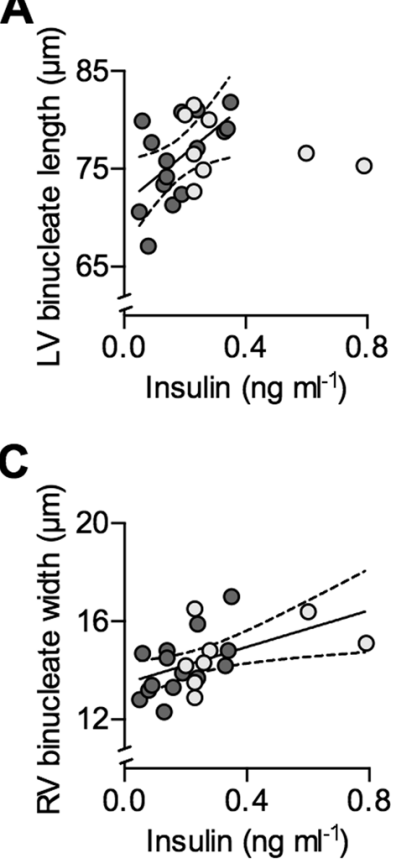

Figure 5

Circulating IGF1 levels predict cardiomyocyte number in Control and IUGR fetal sheep. Following significant correlation within IUGR fetuses $(P<0.05)$, regressions on separate treatment groups were found to be not significantly different, and a single regression was fit between circulating IGF1 levels and (A) RV myocyte number $(Y=0.0006741 \mathrm{X}+0.1393$, $\left.r^{2}=0.1747, P=0.0529\right)$, (B) septum myocyte number $\left(Y=0.001819 X+0.2649, r^{2}=0.4092\right.$, $P=0.0013)$ and (C) LV myocyte number $\left(Y=0.005212 \mathrm{X}+0.805, r^{2}=0.3177 ; P=0.0051\right)$. Linear regression $\pm 95 \%$ confidence intervals are plotted with raw data.

of the myofibers is smaller and that there is less myoblast proliferation; yet, the skeletal muscle maintains the pool of Pax7+ myoblasts with proliferative potential (Yates et al. 2014, Soto et al. 2017, Rozance et al. 2018). Our findings in this study are comparable, with lighter hearts in IUGR

B
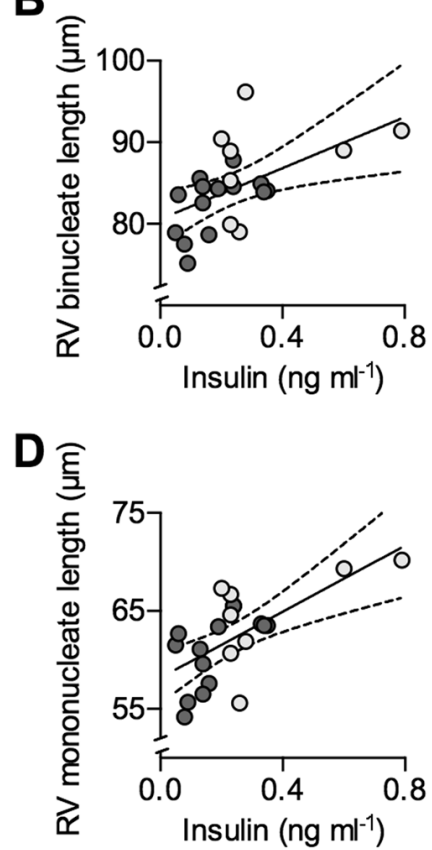

Circulating insulin predict some cardiomyocyte dimensions in Control and IUGR fetal sheep. Following significant correlation within IUGR fetuses $(P<0.05)$, regressions were found to be different by treatment for (A) LV binucleate length, therefore the regression on insulin for IUGR fetuses is plotted $\left(Y=25.41 \mathrm{X}+71.44, r^{2}=0.3321, P=0.0245\right)$ (Control regression was not significant). Regressions for other parameters were not significantly different by treatment, and a single regression was fit between circulating insulin levels and (B) RV binucleate length $(Y=15.63 X+80.57$, $\left.r^{2}=0.2883, P=0.01\right)$, (C) RV binucleate width $(Y=3.731 X+13.46$, $\left.r^{2}=0.2631, P=0.0146\right)$, (D) RV mononucleate length $(Y=16.86 \mathrm{X}+58.18$, $r^{2}=0.4327, P=0.0009$ ). Linear regression $\pm 95 \%$ confidence intervals are

https://joe.bioscientifica.com https://doi.org/10.1530/JOE-18-0382 


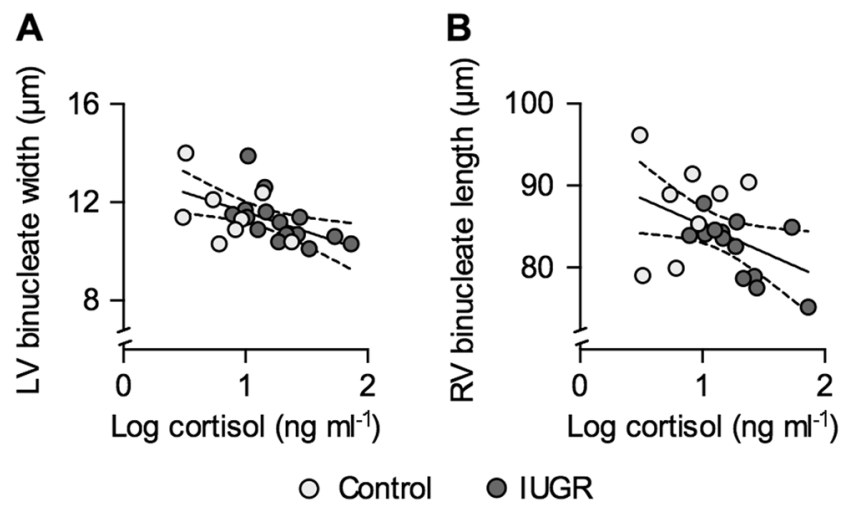

Figure 7

Circulating cortisol predicts some cardiomyocyte dimensions in Control and IUGR fetal sheep. Following significant correlation within IUGR fetuses $(P<0.05)$, regressions on separate treatment groups were found to be not significantly different, and a single regression was fit between circulating cortisol and (A) LV binucleate width $(Y=-1.604 X+13.21$, $\left.r^{2}=0.2778, P=0.0098\right)$ and $(B) R V$ binucleate length $(Y=-6.587 X+91.76$, $r^{2}=0.2031, P=0.0353$ ). Linear regression $\pm 95 \%$ confidence intervals are plotted with raw data.

fetuses, smaller myocytes, lower indices of proliferation and decreased maturation.

Life-long reduction in lean mass (Fall 2011) and cardiomyocyte number (Vranas et al. 2017) suggests that no adaptive mechanism helps the IUGR newborn undergo adequate physiological 'catch-up' of muscle growth. Nevertheless, in near-term IUGR skeletal muscle the pool of Pax7+ myoblasts with proliferative potential is not reduced and in the heart, the mononucleated population of cardiomyocytes capable of proliferating is increased, suggesting opportunity for therapeutic intervention. Indeed, cultured Pax7+ skeletal myoblasts from IUGR fetuses responded much more aggressively to proliferative signals than Control cells in vitro (Soto et al. 2017). As circulating insulin and IGF1 concentrations are reduced, this suggests that an IGF1 rescue strategy in IUGR could yield a rapid increase in myocyte endowment at term (Harding et al. 1994, Sundgren et al. 2003, Eremia et al. 2007, Soto et al. 2017).

Pathway analysis in near-term IUGR skeletal muscle found decreased expression of clusters of genes related to cell cycle regulation (Soto et al. 2017). The most profoundly affected genes include $\mathrm{G} 1$ progression regulators cyclin E2 and p18, initiator of DNA replication Mcm6, G2/M progression regulator Plk1, regulators of commitment to mitosis cyclin B1, cyclin B2 and Cdk1, regulator of nuclear movement and chromosome separation CDC20, spindle assembly quality control molecule MAD2, spindle checkpoint regulator BUB1B, initiator of separation of sister chromatids in mitosis ESPL1 and DNA damage cell cycle arrestor CHK1. We found that many of those genes with reduced expression in skeletal muscle are also reduced in cardiac muscle, including PLK1, cyclin B1, cyclin B2, CDK1, CDC20, MAD2, BUB1B and ESPL1, supporting the parallels in response to in utero challenge between these two types of striated muscle despite differences in preferential nutrient delivery during IUGR.

\section{Hormonal regulation of cardiac growth in IUGR}

Hormonal regulation of growth might help explain similar growth and gene expression patterns in IUGR skeletal muscle and heart despite preservation of nutrient delivery to the myocardium. In order to reduce the rate of spurious findings, we screened cardiac growth parameters against circulating hormone concentrations by performing correlations only within IUGR fetuses, followed up by testing whether regressions between Control and IUGR fetuses were different and, if they were not, performing regression on pooled fetal parameters. These results do not show causality, but indicated potential mechanisms regulating specific aspects of myocyte growth in the nearterm fetal heart.

In IUGR fetuses, IGF1 and insulin levels are half those in Control fetuses. IGF1 is the main endocrine driver of fetal growth (Murray \& Clayton 2013, Hellstrom et al. 2016), is critical to skeletal muscle growth in development (Liu et al. 1993, Mavalli et al. 2010) and is a profound stimulus of cardiomyocyte proliferation in the fetal heart (Sundgren et al. 2003). Fetal heart weight and cardiomyocyte numbers were predicted by circulating IGF1 levels. Circulating insulin levels predicted most myocyte length dimensions as well as one width dimension. Consequently, IGF1 and/or insulin receptors might be therapeutic targets for treatment to increase fetal myocyte replication.

In contrast to IGF1 and insulin, cortisol and norepinephrine levels are more than doubled in nearterm IUGR fetuses. In fetal cardiomyocytes, cortisol has been linked to proliferation (Giraud et al. 2006, Reini et al. 2008, Feng et al. 2013) and enlargement (Lumbers et al. 2005), and also to apoptosis (Reini et al. 2008, Feng et al. 2013). However, cortisol reduced myoblast proliferation and causes myotube atrophy through decreased protein synthesis and increased protein degradation (Morgan et al. 2016). Cortisol in fetal skeletal muscle suppresses IGF1 expression (Li et al. 2002), but not IGF1 receptor 1 expression (Jellyman et al. 2012), and IGF1 opposes the effects of cortisol on skeletal muscle (Glass 2010, Morgan et al. 2016). Circulating cortisol levels negatively predicted 


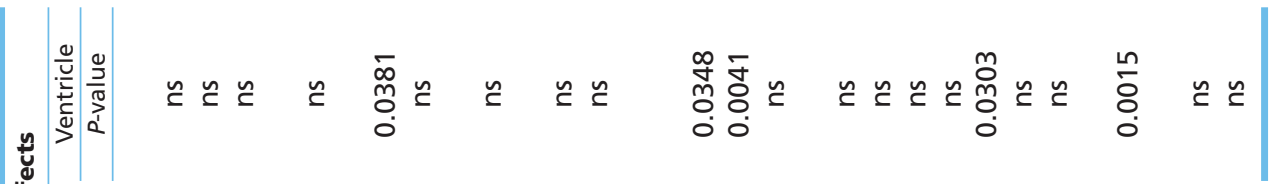

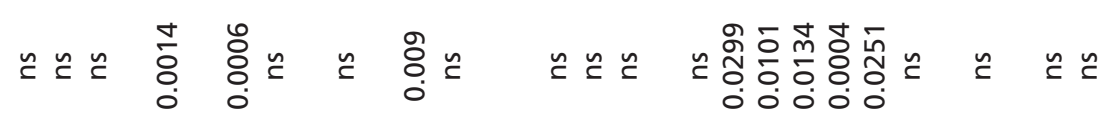

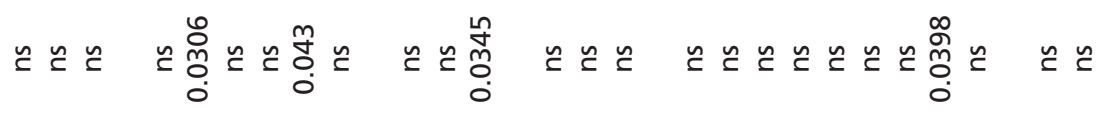

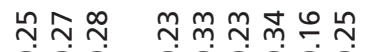

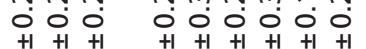

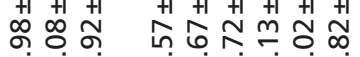

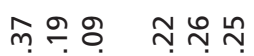

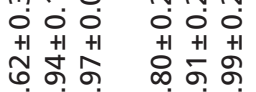

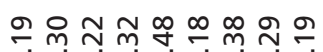
웅 o.

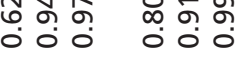

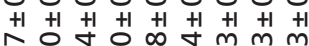

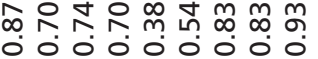

in

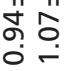
$\geq$

オำ

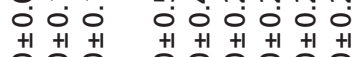

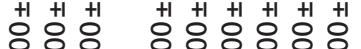

ำ 는

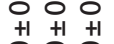

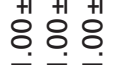

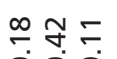
i $0^{\circ} 0^{\circ}$

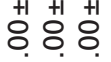

ํํำ ํํำ ○0 0000000

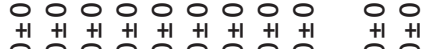

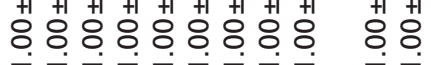
둥 (1) $-\leftarrow$

-i

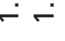

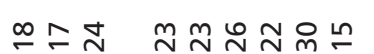

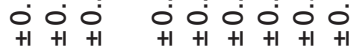

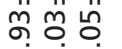

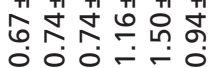

ำ

000

ํํำ

늠ำ ㄷํำ

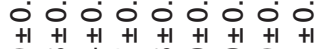

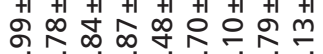

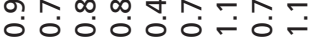

$+0$

ปั ठ্

$\vec{x}$

ฟิธตำ

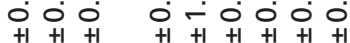

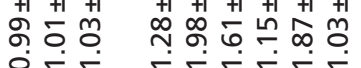

กิำ.

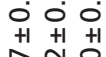

m

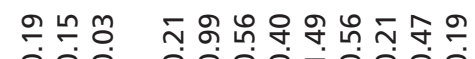

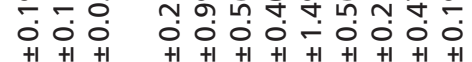

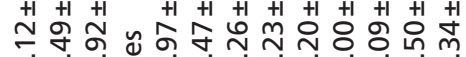

$\circ \stackrel{-}{-1}$

- 00 远

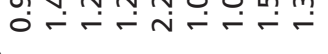

둥

$+1$

ஜำ ஸุ

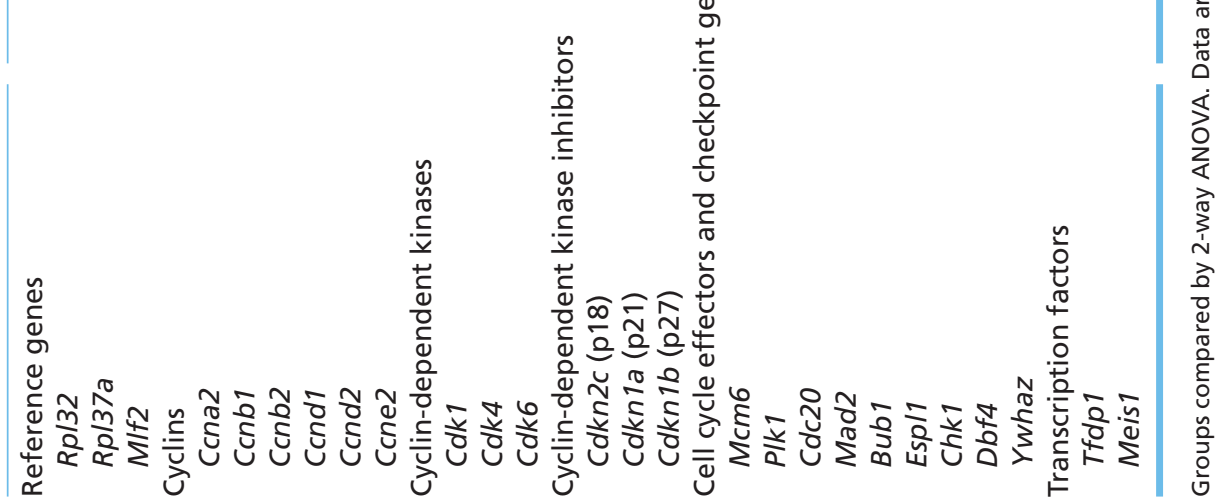

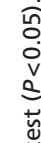


two binucleated myocyte dimension parameters, supporting a role of growth repression in the heart. How cortisol interacts with low levels of IGF1 to suppress growth or induce apoptosis in IUGR skeletal and cardiac muscle remains to be determined.

Norepinephrine is a non-selective adrenergic agonist linked to hypertrophy in adult cardiomyocytes. Phenylephrine, a selective $\alpha$-adrenergic agonist, strongly stimulates hypertrophy in fetal sheep cardiomyocytes. It is notable that we found a reduction in cardiomyocyte size in IUGR fetuses concurrent with elevated norepinephrine, which suggests that cardiac adrenergic signaling is altered in IUGR or that there is a mechanism actively repressing fetal cardiomyocyte growth during placental restriction. Indeed, high circulating fetal norepinephrine inhibits overall fetal growth (Milley 1997, Bassett \& Hanson 1998).

\section{Interpretation of cardiac effects of IUGR}

Body and heart weight were reduced in this study, as is common in models of placental restriction (Louey et al. 2007, Morrison et al. 2007, Tare et al. 2014). Reduction in heart weight relative to body weight, toward which there was a tendency in this study, has been found in carunclectomy-induced IUGR (Bubb et al. 2007). The carunculectomy model is created by surgical excision of placental implantation sites in ewes prior to breeding, which induces a progressive phenotype from early in gestation similar to the environmental model used in this study. This contrasts with fetoplacental embolization, induced in the last third of gestation, in which heart weight relative to body weight is unchanged (Louey et al. 2007) or increased (Murotsuki et al. 1997).

The relative contributions of small myocyte size, inhibited proliferation and less terminal differentiation to overall cardiac undergrowth in IUGR can be estimated by calculating the loss in mass attributable to each difference. Reduced heart weight is due to smaller myocyte size ( 30-55\%), reduced myocyte number ( 20-40\%), changes in non-myocyte components $(\sim 20 \%)$ and reduced terminal differentiation ( 5-10\%; because binucleated cells are larger than mononucleated cells). Reduced proliferation and maturation is common to humans affected by placental insufficiency and animal models of IUGR (Takahashi et al. 1995, Murotsuki et al. 1997, Mayhew et al. 1999, Bubb et al. 2007, Louey et al. 2007, Morrison et al. 2007, Botting et al. 2014).

Although diminished cellular volume due to shorter myocytes in IUGR was the largest contributor to reduced heart weight in this study, there is disagreement among other studies about the role of retarded myocyte enlargement in IUGR hearts. One study in carunclectomized ewes indicates that IUGR reduces mononucleated myocyte length and width, but only binucleated width near term (Morrison et al. 2007); however, these results are confounded by the finding that Control binucleated myocytes shrink in length and width over the period of 132-141dGA. In contrast, no differences in myocyte dimensions have been found in fetoplacental embolization models, which are initiated in the last third of gestation (Bubb et al. 2007, Louey et al. 2007). It may be that the effect of IUGR on cardiomyocyte size occurs over a long period and is only detectable when placental insufficiency is initiated early in gestation.

\section{Differences between LV and RV myocytes}

Due to hemodynamic shunts, both fetal ventricles pump against similar pressure into the systemic circulation and are more alike in mass and geometry in the fetus than at any later age. Despite these similarities, fetal myocyte appear to have a ventricular 'identity': RV cardiomyocytes are larger and less numerous than LV myocytes (Burrell et al. 2003, Jonker et al. 2007). Although these differences were found in this study, the changes induced by IUGR did not vary by ventricular wall, consistent with other studies (Bubb et al. 2007, Jonker et al. 2011, Segar et al. 2013). Relationships shown between circulating hormones and myocyte parameters that are significant only in one ventricle should not be taken as proof of a ventricular 'identity', as causative effects of hormones have not been established in this study. The basis of the apparent ventricular 'identity' remains unknown.

\section{Strengths and limitations of the study}

The ovine model of chronic and progressive placental insufficiency used in this study shares many phenotypic characteristics with human placental insufficiency, including similar patterns of heart and brain sparing, lower rates of amino acid, glucose and oxygen transfer from mother to the fetus, reduced circulating growth factors and elevated catecholamines (Barry et al. 2008). This model also allowed for chronic catheterization of the fetal circulation for fetal blood sampling concurrent with cardiac tissue collection, to correlate in vivo physiological measures with comprehensive morphometric data. Further, cardiomyocytes from left, right and septal ventricular walls were isolated after heart dissociation, which allowed for ventricular-specific comparisons of 
cardiomyocyte number, maturity and size. However, we were not adequately powered to assess sex differences for all measurements in this study, despite reports of sexual dimorphism in cardiomyocyte number related to IUGR (Botting et al. 2018). Further, tissue availability limited further evaluation of downstream signaling activation by insulin and IGF1.

\section{Conclusions}

IUGR fetuses had low circulating insulin and IGF1 levels, high circulating cortisol levels and light bodies and hearts. IUGR cardiomyocytes were smaller, less mature, less active in the cell cycle and less numerous than Control cells, and there was downregulation of cell cycle genes in IUGR hearts. We did not find differences in heart size and cardiomyocyte indices attributable to fetal sex; therefore, sex as a main effect was not included in the final model. Interactions between sex and treatment could not be fully evaluated due to small sample size and should be pursued in future studies. Similarities between heart and skeletal muscle in IUGR leading to reductions in myocyte cell cycle activity, number, size and maturation suggest similarities in regulation of growth, perhaps through IGF1 and insulin signaling, despite differences in nutrient delivery prioritization. Further studies are required to understand the potential of fetal anabolic hormones such as insulin and IGF1 as therapeutic agents to increase myocyte number in hearts of IUGR fetuses.

\section{Declaration of interest}

The authors declare that there is no conflict of interest that could be perceived as prejudicing the impartiality of the research reported.

\section{Funding}

This work was supported by NIH Grants K12 HD057022, R01 HD079404, and The Center for Women's Health Research, University of Colorado School of Medicine (L D B), and R01 HD071068 (S S J).

\section{Acknowledgements}

The authors thank Samantha Louey for critical review of the manuscript.

\section{References}

Adler CP, Friedburg H, Herget GW, Neuburger M \& Schwalb H 1996 Variability of cardiomyocyte DNA content, ploidy level and nuclear number in mammalian hearts. Virchows Archiv 429 159-164.
Alexander BT, Dasinger JH \& Intapad S 2015 Fetal programming and cardiovascular pathology. Comprehensive Physiology 5 997-1025. (https://doi.org/10.1002/cphy.c140036)

Barker DJ \& Thornburg KL 2013 The obstetric origins of health for a lifetime. Clinical Obstetrics and Gynecology 56 511-519. (https://doi. org/10.1097/GRF.0b013e31829cb9ca)

Barry JS, Rozance PJ \& Anthony RV 2008 An animal model of placental insufficiency-induced intrauterine growth restriction. Seminars in Perinatology 32 225-230. (https://doi.org/10.1053/j. semperi.2007.11.004)

Baschat AA \& Hecher K 2004 Fetal growth restriction due to placental disease. Seminars in Perinatology 28 67-80. (https://doi.org/10.1053/j. semperi.2003.10.014)

Bassett JM \& Hanson C 1998 Catecholamines inhibit growth in fetal sheep in the absence of hypoxemia. American Journal of Physiology $\mathbf{2 7 4}$ R1536-R1545. (https://doi.org/10.1152/ajpregu.1998.274.6.R1536)

Bell AW, Wilkening RB \& Meschia G 1987 Some aspects of placental function in chronically heat-stressed ewes. Journal of Developmental Biology 9 17-29.

Bellotti M, Pennati G, De Gasperi C, Bozzo M, Battaglia FC \& Ferrazzi E 2004 Simultaneous measurements of umbilical venous, fetal hepatic, and ductus venosus blood flow in growth-restricted human fetuses. American Journal of Obstetrics and Gynecology 190 1347-1358. (https:// doi.org/10.1016/j.ajog.2003.11.018)

Bergmann O, Zdunek S, Felker A, Salehpour M, Alkass K, Bernard S, Sjostrom SL, Szewczykowska M, Jackowska T, Dos Remedios C, et al. 2015 Dynamics of Cell Generation and Turnover in the Human Heart. Cell 161 1566-1575. (https://doi.org/10.1016/j.cell.2015.05.026)

Botting KJ, McMillen IC, Forbes H, Nyengaard JR \& Morrison JL 2014 Chronic hypoxemia in late gestation decreases cardiomyocyte number but does not change expression of hypoxia-responsive genes. Journal of the American Heart Association 3 e000531. (https://doi. org/10.1161/JAHA.113.000531)

Botting KJ, Loke XY, Zhang S, Andersen JB, Nyengaard JR \& Morrison JL 2018 IUGR decreases cardiomyocyte endowment and alters cardiac metabolism in a sex- and cause-of-IUGR-specific manner. American Journal of Physiology: Regulatory, Integrative and Comparative Physiology 315 R48-R67. (https://doi.org/10.1152/ajpregu.00180.2017)

Brown LD \& Hay WW Jr 2016 Impact of placental insufficiency on fetal skeletal muscle growth. Molecular and Cellular Endocrinology 435 69-77. (https://doi.org/10.1016/j.mce.2016.03.017)

Brown LD, Rozance PJ, Thorn SR, Friedman JE \& Hay WW Jr 2012 Acute supplementation of amino acids increases net protein accretion in IUGR fetal sheep. American Journal of Physiology: Endocrinology and Metabolism 303 E352-E364. (https://doi.org/10.1152/ ajpendo.00059.2012)

Brown LD, Thorn SR, O’Meara MC, Lavezzi JR \& Rozance PJ 2014 A physiological increase in insulin suppresses muscle-specific ubiquitin ligase gene activation in fetal sheep with sustained hypoglycemia. Physiological Reports 2 e12045. (https://doi.org/10.14814/phy2.12045)

Bubb KJ, Cock ML, Black MJ, Dodic M, Boon WM, Parkington HC, Harding R \& Tare M 2007 Intrauterine growth restriction delays cardiomyocyte maturation and alters coronary artery function in the fetal sheep. Journal of Physiology $\mathbf{5 7 8}$ 871-881. (https://doi. org/10.1113/jphysiol.2006.121160)

Burrell JH, Boyn AM, Kumarasamy V, Hsieh A, Head SI \& Lumbers ER 2003 Growth and maturation of cardiac myocytes in fetal sheep in the second half of gestation. Anatomical Record Part A Discoveries in Molecular Cellular and Evolutionary Biology 274 952-961. (https://doi. org/10.1002/ar.a.10110)

Camm EJ, Brain KL, Niu Y, Allison BJ, Botting KJ, Itani N, Skeffington KL, Beck C \& Giussani DA 2015 Chronic fetal hypoxia in ovine pregnancy triggers a fetal origin of heart disease that amplifies with ageing: prevention with maternal antioxidant treatment (abstract). Reproductive Sciences 22 1. (https://doi. org/10.1177/1933719115579630) 
Clubb FJ Jr \& Bishop SP 1984 Formation of binucleated myocardial cells in the neonatal rat. An index for growth hypertrophy. Laboratory Investigation $\mathbf{5 0} 571-577$.

Culpepper C, Wesolowski SR, Benjamin J, Bruce JL, Brown LD, Jonker SS, Wilkening RB, Hay WW Jr \& Rozance PJ 2016 Chronic anemic hypoxemia increases plasma glucagon and hepatic PCK1 mRNA in late-gestation fetal sheep. American Journal of Physiology: Regulatory, Integrative and Comparative Physiology 311 R200-R208. (https://doi. org/10.1152/ajpregu.00037.2016)

de Boo HA \& Harding JE 2006 The developmental origins of adult disease (Barker) hypothesis. Australian and New Zealand Journal of Obstetrics and Gynaecology 46 4-14. (https://doi.org/10.1111/j.1479828X.2006.00506.x)

Eremia SC, de Boo HA, Bloomfield FH, Oliver MH \& Harding JE 2007 Fetal and amniotic insulin-like growth factor-I supplements improve growth rate in intrauterine growth restriction fetal sheep. Endocrinology 148 2963-2972. (https://doi.org/10.1210/en.2006-1701)

Fall CH 2011 Evidence for the intra-uterine programming of adiposity in later life. Annals of Human Biology 38 410-428. (https://doi.org/10.310 9/03014460.2011.592513)

Feng X, Reini SA, Richards E, Wood CE \& Keller-Wood M 2013 Cortisol stimulates proliferation and apoptosis in the late gestation fetal heart: differential effects of mineralocorticoid and glucocorticoid receptors. American Journal of Physiology: Regulatory, Integrative and Comparative Physiology 305 R343-R350. (https://doi.org/10.1152/ ajpregu.00112.2013)

Fernandez-Twinn DS \& Ozanne SE 2010 Early life nutrition and metabolic programming. Annals of the New York Academy of Sciences 1212 78-96. (https://doi.org/10.1111/j.1749-6632.2010.05798.x)

Giraud GD, Louey S, Jonker S, Schultz J \& Thornburg KL 2006 Cortisol stimulates cell cycle activity in the cardiomyocyte of the sheep fetus. Endocrinology 147 3643-3649. (https://doi.org/10.1210/en.2006-0061)

Glass DJ 2010 Signaling pathways perturbing muscle mass. Current Opinion in Clinical Nutrition and Metabolic Care 13 225-229. (https:// doi.org/10.1097/MCO.0b013e32833862df)

Harding JE, Liu L, Evans PC \& Gluckman PD 1994 Insulin-like growth factor 1 alters feto-placental protein and carbohydrate metabolism in fetal sheep. Endocrinology 134 1509-1514. (https://doi.org/10.1210/ endo.134.3.8119193)

Hellstrom A, Ley D, Hansen-Pupp I, Hallberg B, Lofqvist C, van Marter L, van Weissenbruch M, Ramenghi LA, Beardsall K, Dunger D, et al. 2016 Insulin-like growth factor 1 has multisystem effects on foetal and preterm infant development. Acta Paediatrica 105 576-586. (https:// doi.org/10.1111/apa.13350)

Huttenbach Y, Ostrowski ML, Thaller D \& Kim HS 2001 Cell proliferation in the growing human heart: MIB-1 immunostaining in preterm and term infants at autopsy. Cardiovascular Pathology 10 119-123. (https:// doi.org/10.1016/S1054-8807(01)00065-5)

Jellyman JK, Martin-Gronert MS, Cripps RL, Giussani DA, Ozanne SE, Shen QW, Du M, Fowden AL \& Forhead AJ 2012 Effects of cortisol and dexamethasone on insulin signalling pathways in skeletal muscle of the ovine fetus during late gestation. PLOS ONE 7 e52363. (https:// doi.org/10.1371/journal.pone.0052363)

Jonker SS, Zhang L, Louey S, Giraud GD, Thornburg KL \& Faber JJ 2007 Myocyte enlargement, differentiation, and proliferation kinetics in the fetal sheep heart. Journal of Applied Physiology 102 1130-1142. (https://doi.org/10.1152/japplphysiol.00937.2006)

Jonker SS, Scholz TD \& Segar JL 2011 The effect of adrenalectomy on the cardiac response to subacute fetal anemia. Canadian Journal of Physiology and Pharmacology 89 79-88. (https://doi.org/10.1139/Y10-108)

Jonker SS, Louey S, Giraud GD, Thornburg KL \& Faber JJ 2015 Timing of cardiomyocyte growth, maturation, and attrition in perinatal sheep. FASEB Journal 29 4346-4357. (https://doi.org/10.1096/fj.15-272013)

Kim HD, Kim DJ, Lee IJ, Rah BJ, Sawa Y \& Schaper J 1992 Human fetal heart development after mid-term: morphometry and ultrastructural study. Journal of Molecular and Cellular Cardiology 24 949-965. (https:// doi.org/10.1016/0022-2828(92)91862-Y)

Li J, Forhead AJ, Dauncey MJ, Gilmour RS \& Fowden AL 2002 Control of growth hormone receptor and insulin-like growth factor-I expression by cortisol in ovine fetal skeletal muscle. Journal of Physiology $\mathbf{5 4 1}$ 581-589. (https://doi.org/10.1113/jphysiol.2002.016402)

Limesand SW, Rozance PJ, Zerbe GO, Hutton JC \& Hay WW Jr 2006 Attenuated insulin release and storage in fetal sheep pancreatic islets with intrauterine growth restriction. Endocrinology 147 1488-1497. (https://doi.org/10.1210/en.2005-0900)

Limesand SW, Rozance PJ, Smith D \& Hay WW Jr 2007 Increased insulin sensitivity and maintenance of glucose utilization rates in fetal sheep with placental insufficiency and intrauterine growth restriction. American Journal of Physiology: Endocrinology and Metabolism 293 E1716-E1725. (https://doi.org/10.1152/ajpendo.00459.2007)

Liu JP, Baker J, Perkins AS, Robertson EJ \& Efstratiadis A 1993 Mice carrying null mutations of the genes encoding insulin-like growth factor I (Igf-1) and type 1 IGF receptor (Igf1r). Cell 75 59-72.

Louey S, Jonker SS, Giraud GD \& Thornburg KL 2007 Placental insufficiency decreases cell cycle activity and terminal maturation in fetal sheep cardiomyocytes. Journal of Physiology $\mathbf{5 8 0} 639-648$. (https://doi.org/10.1113/jphysiol.2006.122200)

Lumbers ER, Boyce AC, Joulianos G, Kumarasamy V, Barner E, Segar JL \& Burrell JH 2005 Effects of cortisol on cardiac myocytes and on expression of cardiac genes in fetal sheep. American Journal of Physiology: Regulatory, Integrative and Comparative Physiology $\mathbf{2 8 8}$ R567-R574. (https://doi.org/10.1152/ajpregu.00556.2004)

Lumbers ER, Kim MY, Burrell JH, Kumarasamy V, Boyce AC, Gibson KJ, Gatford KL \& Owens JA 2009 Effects of intrafetal IGF-I on growth of cardiac myocytes in late-gestation fetal sheep. American Journal of Physiology: Endocrinology and Metabolism 296 E513-E519. (https://doi. org/10.1152/ajpendo.90497.2008)

Marconi AM \& Paolini CL 2008 Nutrient transport across the intrauterine growth-restricted placenta. Seminars in Perinatology 32 178-181. (https://doi.org/10.1053/j.semperi.2008.02.007)

Mavalli MD, DiGirolamo DJ, Fan Y, Riddle RC, Campbell KS, van Groen T, Frank SJ, Sperling MA, Esser KA, Bamman MM, et al. 2010 Distinct growth hormone receptor signaling modes regulate skeletal muscle development and insulin sensitivity in mice. Journal of Clinical Investigation 120 4007-4020. (https://doi.org/10.1172/ JCI42447)

Mayhew TM, Gregson C \& Fagan DG 1999 Ventricular myocardium in control and growth-retarded human fetuses: growth in different tissue compartments and variation with fetal weight, gestational age, and ventricle size. Human Pathology 30 655-660. (https://doi.org/10.1016/ S0046-8177(99)90090-4)

Milley JR 1997 Ovine fetal metabolism during norepinephrine infusion. American Journal of Physiology 273 E336-E347. (https://doi. org/10.1152/ajpendo.1997.273.2.E336)

Morgan SA, Hassan-Smith ZK, Doig CL, Sherlock M, Stewart PM \& Lavery GG 2016 Glucocorticoids and 11beta-HSD1 are major regulators of intramyocellular protein metabolism. Journal of Endocrinology 229 277-286. (https://doi.org/10.1530/JOE-16-0011)

Morrison JL, Botting KJ, Dyer JL, Williams SJ, Thornburg KL \& McMillen IC 2007 Restriction of placental function alters heart development in the sheep fetus. American Journal of Physiology: Regulatory, Integrative and Comparative Physiology 293 R306-R313. (https://doi.org/10.1152/ajpregu.00798.2006)

Murotsuki J, Challis JR, Han VK, Fraher LJ \& Gagnon R 1997 Chronic fetal placental embolization and hypoxemia cause hypertension and myocardial hypertrophy in fetal sheep. American Journal of Physiology 272 R201-R207. (https://doi.org/10.1152/ajpregu.1997.272.1.R201)

Murray PG \& Clayton PE 2013 Endocrine control of growth. American Journal of Medical Genetics Part C: Seminars in Medical Genetics 163C 76-85. (https://doi.org/10.1002/ajmg.c.31357) (c) 2018 Society for Endocrinology Published by Bioscientifica Ltd. Printed in Great Britain 
Phillips DI, Barker DJ, Hales CN, Hirst S \& Osmond C 1994 Thinness at birth and insulin resistance in adult life. Diabetologia 37 150-154. (https://doi.org/10.1007/s001250050086)

Poudel R, McMillen IC, Dunn SL, Zhang S \& Morrison JL 2015 Impact of chronic hypoxemia on blood flow to the brain, heart, and adrenal gland in the late-gestation IUGR sheep fetus. American Journal of Physiology: Regulatory, Integrative and Comparative Physiology $\mathbf{3 0 8}$ R151-R162. (https://doi.org/10.1152/ajpregu.00036.2014)

Regnault TR, de Vrijer B, Galan HL, Wilkening RB, Battaglia FC \& Meschia G 2007 Development and mechanisms of fetal hypoxia in severe fetal growth restriction. Placenta 28 714-723. (https://doi. org/10.1016/j.placenta.2006.06.007)

Reini SA, Dutta G, Wood CE \& Keller-Wood M 2008 Cardiac corticosteroid receptors mediate the enlargement of the ovine fetal heart induced by chronic increases in maternal cortisol. Journal of Endocrinology 198 419-427. (https://doi.org/10.1677/JOE-08-0022)

Rowe RW \& Goldspink G 1969 Muscle fibre growth in five different muscles in both sexes of mice. Journal of Anatomy 104 519-530.

Rozance PJ, Zastoupil L, Wesolowski SR, Goldstrohm DA, Strahan B, CreeGreen M, Sheffield-Moore M, Meschia G, Hay WW Jr, Wilkening RB, et al. 2018 Skeletal muscle protein accretion rates and hindlimb growth are reduced in late gestation intrauterine growth-restricted fetal sheep. Journal of Physiology 596 67-82. (https://doi.org/10.1113/JP275230)

Segar JL, Volk KA, Lipman MH \& Scholz TD 2013 Thyroid hormone is required for growth adaptation to pressure load in the ovine fetal heart. Exp Physiol 98 722-733. (https://doi.org/10.1113/ expphysiol.2012.069435)

Smolich JJ, Walker AM, Campbell GR \& Adamson TM 1989 Left and right ventricular myocardial morphometry in fetal, neonatal, and adult sheep. American Journal of Physiology 257 H1-H9. (https://doi. org/10.1152/ajpheart.1989.257.1.H1)

Soto SM, Blake AC, Wesolowski SR, Rozance PJ, Barthel KB, Gao B, Hetrick B, McCurdy CE, Garza NG, Hay WW Jr, et al. 2017 Myoblast replication is reduced in the IUGR fetus despite maintained proliferative capacity in vitro. Journal of Endocrinology 232 475-491. (https://doi.org/10.1530/JOE-16-0123)
Sundgren NC, Giraud GD, Schultz JM, Lasarev MR, Stork PJ \& Thornburg KL 2003 Extracellular signal-regulated kinase and phosphoinositol-3 kinase mediate IGF-1 induced proliferation of fetal sheep cardiomyocytes. American Journal of Physiology: Regulatory, Integrative and Comparative Physiology 285 R1481-R1489. (https://doi. org/10.1152/ajpregu.00232.2003)

Takahashi N, Nishida H, Arai T \& Kaneda Y 1995 Abnormal cardiac histology in severe intrauterine growth retardation infants. Acta Paediatrica Japonica 37 341-346. (https://doi.org/10.1111/j.1442200X.1995.tb03326.x)

Tare M, Parkington HC, Wallace EM, Sutherland AE, Lim R, Yawno T, Coleman HA, Jenkin G \& Miller SL 2014 Maternal melatonin administration mitigates coronary stiffness and endothelial dysfunction, and improves heart resilience to insult in growth restricted lambs. Journal of Physiology 592 2695-2709. (https://doi. org/10.1113/jphysiol.2014.270934)

Thureen PJ, Trembler KA, Meschia G, Makowski EL \& Wilkening RB 1992 Placental glucose transport in heat-induced fetal growth retardation. American Journal of Physiology 263 R578-R585. (https:// doi.org/10.1152/ajpregu.1992.263.3.R578)

Vranas S, Heinemann GK, Liu H, De Blasio MJ, Owens JA, Gatford KL \& Black MJ 2017 Small size at birth predicts decreased cardiomyocyte number in the adult ovine heart. Journal of Developmental Origins of Health and Disease 8 618-625. (https://doi.org/10.1017/ S2040174417000381)

Widdowson EM, Crabb DE \& Milner RD 1972 Cellular development of some human organs before birth. Archives of Disease in Childhood $\mathbf{4 7}$ 652-655. (https://doi.org/10.1136/adc.47.254.652)

Yates DT, Clarke DS, Macko AR, Anderson MJ, Shelton LA, Nearing M, Allen RE, Rhoads RP \& Limesand SW 2014 Myoblasts from intrauterine growth-restricted sheep fetuses exhibit intrinsic deficiencies in proliferation that contribute to smaller semitendinosus myofibres. Journal of Physiology 592 3113-3125. (https://doi. org/10.1113/jphysiol.2014.272591)

Zak R 1974 Development and proliferative capacity of cardiac muscle cells. Circulation Research 35 (Supplement II) 17-26.

Received in final form 15 August 2018

Accepted 24 August 2018

Accepted Preprint published online 24 August 2018
() 2018 Society for Endocrinology Published by Bioscientifica Ltd. Printed in Great Britain 